\title{
Comparison of physician outcome measures and patients' perception of benefits of inpatient neurorehabilitation
}

\author{
S G M Edwards, E D Playford, J C Hobart, A J Thompson
}

Rehabilitation aims to reduce the impact of disease, within the limitations imposed by available resources and the underlying disease. ${ }^{1}$ Measuring rehabilitation is difficult. ${ }^{2}$ Rating scales of impairment, disability, and handicap are often used but only partially reflect the rehabilitation process, tending to be "physician oriented." Rehabilitation is a patient based educational process working towards self management. ${ }^{2}$ Therefore, patient oriented measures should be used, as it is only the patients themselves who truly appreciate the impact of their illness, ${ }^{3}$ and the benefits from rehabilitation. The visual analogue scale is a patient based measuring tool that can be used to answer a variety of questions.

We evaluated how much the traditional, physician oriented measures reflect the benefit perceived by patients, as measured on a visual analogue scale, within the setting of a neurorehabilitation inpatient unit.

\section{Participants, methods, and results}

Our study comprised 773 consecutive patients (mean age 47 (range 16-85) years) admitted to the National Hospital for Neurology and Neurosurgery's neurorehabilitation unit between June 1996 and May 2001. This 18 bed unit specialises in intensive, relatively short stay, individually tailored, goal oriented rehabilitation of patients with predominantly physical neurological deficits. ${ }^{4}$ We excluded 31 patients whose lengths of stay were less than 11 days (period of rehabilitation was not adequate). The median length of stay for the remaining 742 patients was 25 (11-149) days.

We categorised patients into four diagnostic groups: multiple sclerosis (305 patients), stroke (149), spinal cord syndromes (144), and all other conditions (144). Overall the patients improved significantly $(\mathrm{P}<0.001$, paired $t$ tests $)$ on all physician outcome measures: functional independence measure motor score (58.6 (SD 19.2) at admission, 73.4 (17.2) at discharge), cognitive score (29.8 (6.4) v 31.2 (5.1)), total score (88.4 (22.0) v $104.6(20.0))$, and Barthel score (11.9 (5.2) v 16.1 (4.8)). Effect sizes were 0.76, 0.22, 0.73, and 0.80 respectively. Improvements in all four cohorts were similar.

At discharge, 682 patients were asked to rate their degree of perceived benefit on a visual analogue scale, a line ranging from 0 to 10 (high score indicates greater benefit). Patients with visual, cognitive, or language deficits $(n=60)$, unable to carry out the task, were excluded. Patients' perceived benefit from rehabilitation programmes was high, mean 8.3 (2.0) (multiple sclerosis 8.0, stroke 8.3, spinal cord 8.5, others 8.5). Correlations of visual analogue scores and disability change scores were low (Pearson's coefficient for change in functional independence measure, motor score 0.240 , cognitive score 0.072 , total score 0.238 ; Barthel score 0.278).

\section{Comment}

Physician outcome measures relate poorly with patients' perceived benefit from inpatient neurorehabilitation as measured on a visual analogue scale. Visual analogue scales are an established tool in the measurement of a range of symptoms, most notably pain. They have also been used to assess global outcome in stroke rehabilitation. ${ }^{5}$ They are quick and easy to administer but are susceptible to some bias, with some patients likely to give higher scores through a desire to please.

Patient based scores are likely to reflect functional improvement, and patients in this study improved functionally and reported a high level of perceived benefit on the visual analogue scale. The low correlation of visual analogue scale with the functional outcome measures indicates that these measures reflect only a small part of patients' perceived benefit. Conventional outcome measures are likely to underestimate the benefit of rehabilitation, with issues such as patients' coping strategies and self efficacy being ignored. Work is needed to more accurately define the areas of health that rehabilitation affects, so that interventions and services can be more specific and effective.

Contributors: SGME analysed the data. SGME and EDP drafted the article.JCH helped with interpretation of the data and statistical analysis. AJT was responsible for the concept and design and is guarantor for the study.

Funding: None

Competing interests: None declared.

1 Wade DT. Measurement in neurological rehabilitation. Oxford: Oxford University Press, 1992

2 Wade DT, de Jong BA. Recent advances in rehabilitation. BMJ 2000;320:1385-8.

3 Hobart JC, Freeman JA, Lamping DL. Physician and patient-oriented outcomes in progressive neurological disease: which to measure? Curr Opin Neurol 1996;9:441-4.

4 Freeman JA, Playford ED, Nicholas RS, Thompson AJ. A neurological rehabilitation unit: audit of activity and outcome. $J R$ Coll Phys Lond 1996;30:21-6.

5 Indredavik B, Bakke F, Slordahl SA, Rokseth R, Haheim LL. Stroke unit treatment improves long-term quality of life: a randomized controlled trial. Stroke 1998;29:895-9.

(Accepted 21 May 2002)

\section{Endpiece}

Testing a country's prosperity

The prosperity of a country can be seen simply in how it treats its old people.

Nachman of Bratslav (1770-1811), leading Polish Hasidic rabbi and ascetic

Submitted by Fred Charatan,

retired geriatric physician, Florida

\author{
Neurorehabilitation \\ Unit, National \\ Hospital for \\ Neurology and \\ Neurosurgery, \\ Queen Square, \\ London \\ WC1N 3BG \\ S G M Edwards \\ specialist registrar \\ Institute of \\ Neurology, National \\ Hospital for \\ Neurology and \\ Neurosurgery \\ E D Playford \\ senior lecturer in \\ neurology and \\ neuro-rehabilitation \\ A J Thompson \\ professor of neurology \\ and \\ neuro-rehabilitation \\ Derriford Hospital, \\ Plymouth PL6 8DH \\ J C Hobart \\ consultant neurologist \\ Correspondence to: \\ A J Thompson \\ A.Thompson@ \\ ion.ucl.ac.uk
}

BMJ 2002;324:1493 